\title{
Avaliação da Acurácia dos Métodos de Punção Aspirativa por Agulha Fina e Core Biopsy Guiadas por Ultra-som de acordo com o Tamanho da Lesão Mamária Suspeita de Malignidade.
}

Autor: Alexandre de Almeida Barra

Orientador: Prof. Dr. Cezar Alencar de Lima Rezende

Tese de doutorado apresentada ao Curso de Pós-Graduação em Medicina (Área de concentração em Ginecologia e Obstetrícia) da Faculdade de Medicina da Universidade Federal de Minas Gerais, UFMG, em 16 de maio de 2003.

Objetivo: Comparar a acurácia da punção aspirativa por agulha fina (PAAF), da core biopsy e de ambos associados em paralelo de acordo com o tamanho da lesão mamária suspeita de malignidade.

Pacientes e Métodos: Foram incluídas no estudo 264 pacientes portadoras de lesões mamárias suspeitas de malignidade avaliadas no período de agosto de 1997 à agosto de 2002. A punção aspirativa por agulha fina e a core biopsy guiadas por ultra-som foram realizadas, simultaneamente, pelo mesmo examinador, nesta ordem cronológica. As lesões foram divididas em quatro grupos de acordo com o tamanho estabelecido pelo exame histopatológico do espécime cirúrgico em: lesões menores que $1 \mathrm{~cm}$ (22), lesões entre 1 e $2 \mathrm{~cm}$ (55), lesões entre 2 e $5 \mathrm{~cm}$ (135) e lesões maiores que $5 \mathrm{~cm}$ (52). Os testes de validade foram aplicados para a PAAF, core biopsy e após associação de ambos em paralelo considerando todas as lesões e para cada grupo separadamente, utilizando o exame histopatológico do espécime cirúrgico como padrão ouro.

Resultados: O diagnóstico após remoção completa das lesões mostrou 222 (84\%) casos malignos e $42(16 \%)$ benignos, sendo 245 (93\%) palpáveis e 19 (7,0\%) não palpáveis. Para lesões menores que $1 \mathrm{~cm}$, a sensibilidade absoluta e completa, especificidade e taxa de material inadequado foram estatisticamente semelhantes entre a PAAF, core biopsy e ambos associados em pararelo ( $p>0,05)$. Nas lesões entre 1 e $2 \mathrm{~cm}$ a PAAF apresentou sensibilidade absoluta e completa, especificidade e taxa de material inadequado estatisticamente semelhante à core biopsy $(\mathrm{p}>0,05)$. A associa- ção dos métodos mostrou sensibilidade absoluta $(p=0,007)$ e taxa de material inadequado $(p=0,03)$ estatisticamente superior à PAAF, o mesmo não acontecendo comparando-se a associação com a core biopsy empregada isoladamente que não mostrou diferença estatística em nenhum parâmetro avaliado. Para lesões entre 2 e $5 \mathrm{~cm}$ os resultados foram semelhantes aos encontrados quando consideradas todas as 264 lesões. A core biopsy apresentou sensibilidade absoluta estatisticamente superior $(\mathrm{p}<0,001)$ e taxa de material inadequado estatisticamente inferior $(p<0,007)$ em relação à PAAF. A associação dos métodos mostrou sensibilidade estatisticamente superior ao emprego isolado de cada um deles $(\mathrm{p}<0,05)$. Para lesões maiores que $5 \mathrm{~cm}$ todos os resultados da PAAF e core biopsy foram estatisticamente semelhantes $(p>0,05)$. A associação dos métodos somente apresentou resultado estatisticamente superior para sensibilidade absoluta $(p=0,04)$ comparada com a PAAF empregada isoladamente.

Conclusão: A associação dos métodos é vantajosa na abordagem de lesões mamárias suspeitas de malignidade considerando todos os grupos de lesões maiores que $1 \mathrm{~cm}$. Entretanto, nas lesões menores que $1 \mathrm{~cm}$ os resultados foram semelhantes entre a PAAF, core biopsy e ambos associados, identificando um grupo de lesão que apresenta resultados inferiores quando qualquer modalidade de punção-biópsia da mama é empregada.

Palavras-chave: Biópsias por agulha. Mama: câncer. Mama: doenças benignas.

\section{Repercussão do Estresse Pré-natal por Contenção no Resultado da Prenhez de Ratas Diabéticas}

Autora: Silvana Andréa Molina

Orientadora: Prof ${ }^{a}$ Dr $^{a}$ Marilza Vieira Cunha Rudge

Co-orientadora: Prof ${ }^{a}$ Dr $^{\mathrm{a}}$ Ione Pellegatti Lemonica

Tese de Doutorado apresentada no Programa de Pós-Graduação do Departamento de Ginecologia e Obstetrícia da Faculdade de Medicina de Botucatu - UNESP, em 17 de julho de 2003.

\section{Resumo}

O objetivo do presente trabalho foi estudar a influência do estresse materno por contenção no resultado da prenhez em ratas diabéticas, quantificando a corticosterona, dimensionando a duração da prenhez, o número total de filhotes, o número médio de filhotes por rata, a propor- ção macho e fêmea, o peso médio do filhote ao nascimento, o peso da ninhada, a mortalidade perinatal e o desenvolvimento físico da prole: peso corpóreo, aparecimento de penugem e pelos, desdobramento de orelhas, erupção de dentes, abertura de olhos, descida de testículos e abertura vaginal e o comportamento da prole: 